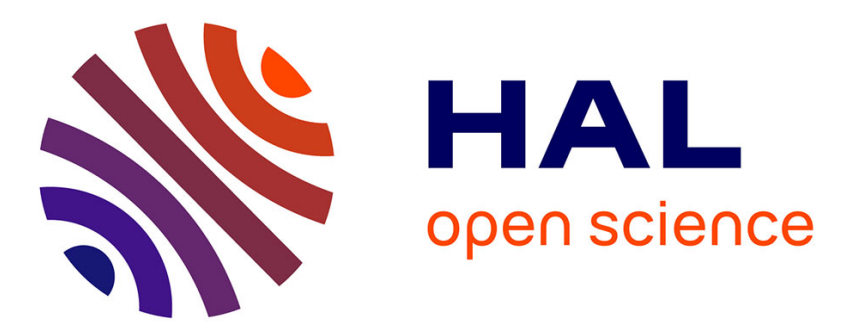

\title{
Origin of the central magnetic anomaly at the Haughton impact structure, Canada
}

\author{
Yoann Quesnel, Jérôme Gattacceca, Gordon R. Osinski, Pierre Rochette
}

\section{To cite this version:}

Yoann Quesnel, Jérôme Gattacceca, Gordon R. Osinski, Pierre Rochette. Origin of the central magnetic anomaly at the Haughton impact structure, Canada. Earth and Planetary Science Letters, 2013, 367, pp.116-122. 10.1016/j.epsl.2013.02.032 . hal-02003610

\section{HAL Id: hal-02003610 https://hal.science/hal-02003610}

Submitted on 1 Feb 2019

HAL is a multi-disciplinary open access archive for the deposit and dissemination of scientific research documents, whether they are published or not. The documents may come from teaching and research institutions in France or abroad, or from public or private research centers.
L'archive ouverte pluridisciplinaire HAL, est destinée au dépôt et à la diffusion de documents scientifiques de niveau recherche, publiés ou non, émanant des établissements d'enseignement et de recherche français ou étrangers, des laboratoires publics ou privés. 


\title{
Origin of the central magnetic anomaly at the Haughton impact structure, Canada
}

\author{
Y. Quesnel ${ }^{\mathrm{a}}$, J. Gattacceca ${ }^{\mathrm{a}, \mathrm{b}}$, G. R. Osinski ${ }^{\mathrm{c}}$, P. Rochette ${ }^{\mathrm{a}}$ \\ ${ }^{a}$ Aix-Marseille Univ, CNRS, CEREGE, UMR 7330, Europole Mediterraneen de l'Arbois, \\ BP80, 13545 Aix-en-Provence cedex 04, France \\ ${ }^{b}$ Department of Earth, Atmospheric, and Planetary Sciences, Massachusetts Institute of \\ Technology, 77 Massachusetts Avenue, Cambridge, MA 02139, USA \\ ${ }^{c}$ Centre for Planetary Science and Exploration, Depts. Earth Sciences 83 Physics and \\ Astronomy, University of Western Ontario, 1151 Richmond Street, London, Ontario, \\ N6A 5B7, Canada
}

\section{Abstract}

The $23 \mathrm{~km}$-diameter well-preserved Haughton impact structure shows a rather unique combination of a positive magnetic anomaly with a negative gravity anomaly over the center of its central uplift. Using a new ground magnetic dataset and several modeling approaches, we investigate the properties and geometry of its central magnetized source. Our results confirm that a kmsized magnetic body with a narrow near-surface extension is necessary to account for the anomaly. Additional measurements of rock magnetic properties of samples of all lithologies encountered in and outside the crater show that the target sedimentary rocks and the vast majority of the Precambrian basement rocks cannot be the source of the magnetic anomaly. While in larger impact structures such magnetic anomalies are often explained by magmatic mafic intrusions or highly magnetic glass lenses in the impact melt rocks, we propose that impact-generated hydrothermal activity enhanced the magnetization of the highly-porous unmelted uplifted basement rocks. Such a 
process may be considered for the interpretation of the geophysical signature of planetary impact craters.

Keywords: Haughton impact structure, magnetic anomaly, rock magnetism, modeling, hydrothermalism

\section{Introduction}

Impact cratering processes on planetary surfaces involve excavation and displacement of target formations that lead to a transient cavity (Melosh, 1989). Then, depending on the projectile size, a central uplift of variably shocked and heated target rocks forms, in addition to crater wall collapse through faulting (Grieve, 1987). Interaction of hot impact-affected rocks with surface fluids can subsequently lead to post-impact hydrothermal activity. Magmatism, sedimentation and erosion are also important processes on the Earth and other planets leading to obscure many impact-related features (e.g., Frey et al., 2001; Buczkowski et al., 2005). In such cases, geophysical investigations can provide constraints on the buried structure (e.g., Pilkington and Grieve, 1992; Pilkington and Hildebrand, 2000; Langlais and Thébault, 2011).

The Haughton impact structure, located Devon Island, Nunavut, Canada (Figure 1) is one of the best preserved medium-size (23 km apparent crater diameter) complex impact structures on Earth. The impact occurred $39 \mathrm{Ma}$ ago in a target formation composed of a $\sim 2-\mathrm{km}$ thick sequence of Lower Paleozoic sedimentary rocks of the Arctic Platform overlying Precambrian metamorphic basement of the Canadian Shield (Robertson and Sweeney, 1983; Bischoff and Oskierski, 1988; Hickey et al., 1988; Metzler et al., 1988; Re- 
deker and Stoeffler, 1988; Osinski et al., 2005b). Clast-rich impact melt rocks filled the crater and impact-related hydrothermal activity took place (Osinski et al., 2005a). A large amount of these impactites were eroded or covered by lacustrine sediments during the Miocene (the Haughton Formation; Figure 1). Later, glacial-interglacial erosion periods modified the landscape, which is now only affected by seasonal glacial and periglacial processes.

Ground magnetic and gravity measurements were carried out within the central part of the crater by Robertson and Sweeney (1983) and Pohl et al. (1988). A $24 \mathrm{~km}$ diameter negative Bouguer gravity anomaly was discovered over the crater with a local minimum over the center. The latter coincides with an intense positive magnetic anomaly. This feature is not common for impact structures of the same size or smaller (Pilkington and Grieve, 1992; Henkel et al., 2002; Shah et al., 2005; Ugalde et al., 2007). Using a simple cone-shape model with a 1-km deep planar root, Pohl et al. (1988) suggested that this low-density highly magnetic local volume of rock underwent large degassing increasing the porosity, and acquired a coherent remanent magnetization during cooling after the shock. Robertson and Sweeney (1983) did not exclude shock remanent magnetization or normal magnetic contrast between the Precambrian basement rocks and the Paleozoic sedimentary formations. Both authors modeled the impact structure with a central uplift, which was partially evidenced by seismic investigations performed on the western flank of the crater (Scott and Hajnal, 1988). Subsequent structural mapping has shown that Haughton possesses a morphologically subdued central uplift feature (Osinski and Spray, 2005). Recent airborne magnetic surveys delivered additional data that cover the whole crater but no detailed modeling of the 
central magnetic anomaly has been done (Glass et al., 2012, and references within). Therefore the exact geometry of the top of this body, as well as its geological significance, are still unknown.

\section{Methods}

In 2010, we performed a new ground magnetic survey to better characterize the central magnetic anomaly of the Haughton impact structure. A Geometrics G858 MagMapper cesium vapor magnetometer was used to measure the intensity of the geomagnetic field vector (total-field, TF) with a sensor at $1.90 \mathrm{~m}$ above the ground. A $1 \mathrm{~Hz}$ sampling was used along kilometric walking profiles crossing the peak of the magnetic anomaly (located in 424677E, $8367960 \mathrm{~N}$, and denoted 'M' on Figure 1 and 2A). Additional discrete measurements were performed. Using our own base station and the data from the Resolute magnetic observatory (distant of $170 \mathrm{~km}$ from Haughton), we were able to properly remove the external and core field signals from our TF measurements to produce a magnetic field anomaly map of the Haughton central area at ground level (Figure 2B). Finally, a local 120 m-long E-W gradient profile was performed over the maximum of the magnetic anomaly (Figure 2C).

These ground magnetic field data were used to investigate, by modeling, the magnetized source of this anomaly. Three modeling approaches were used. First, the possible sources of the magnetic anomaly were forward modeled using uniformly magnetized rectangular prisms (e.g., Quesnel et al., 2008). Their parameters (top and bottom depths, lateral coordinates, total magnetization) were adjusted by a semi-automatic trial and error approach, 
starting from a single deep (and thick) body (that creates the long wavelength of the anomaly). New subsequent (shallow) prisms were then added (and parameters adjusted) until a satisfying model was reached. To estimate the model accuracy, the following Fit parameter was used:

$$
\text { Fit }=100 *\left[1-\sqrt{\frac{\left(\Delta B_{\text {obs }}-\Delta B_{\text {pred }}\right)^{2}}{\Delta B_{\text {obs }}{ }^{2}}}\right]
$$

where $\Delta B_{o b s}$ and $\Delta B_{p r e}$ correspond to the observed and predicted magnetic anomaly values, respectively. The second approach is the Standard Euler Deconvolution (SED) method (Reid et al., 1990), which was applied over the maximum of the anomaly (but excluding the local gradient profile). It gives a range of source depth rather than a real and single source depth. The last modeling approach is the GM-SYS module of the GEOSOFT Inc Oasis montaj software (mainly based on Campbell, 1983). It was applied to all profiles to invert parameters of $2 \mathrm{D}$ bodies with more 'geological' shapes.

The magnetic susceptibility and natural remanent magnetization (NRM) of 289 samples of the Lower Paleozoic sediments (186 from inside and 103 from outside the impact structure) and 337 samples of the Precambrian basement (316 from inside and 21 from outside the crater) were measured using either a portable SM30 susceptibilimeter from ZH Instruments, or a KLY2 susceptibilimeter from AGICO for susceptibility, and for NRM either a $2 \mathrm{G}$ Entreprises 775R magnetometer or a Molspin Minispin magnetometer (for large samples). In order to recover the direction of the paleofield at the time of the impact, we sampled 20 decimetric oriented clasts (13 of Paleozoic sediments and 7 of basement) from two sites located $3 \mathrm{~km}$ apart in the clast-rich impact-melt rocks (Figure 1). Thermal (in a MMTD furnace) or alternating 
field (with an on-line system in the $2 \mathrm{G}$ magnetometer) stepwise demagnetizations were used. Characteristic remanent magnetizations were evaluated by principal component analysis using Paleomac software (Cogné, 2003).

\section{Results and Interpretation}

\subsection{Magnetic field anomaly}

The central magnetic anomaly reaches a maximum of $900 \mathrm{nT}$ (point M in Figure 1 and 2B) while the surroundings globally show a negative magnetic anomaly signal (down to $-100 \mathrm{nT}$ ). The total wavelength of the central magnetic anomaly corresponds to about $1.2 \mathrm{~km}$ in all directions, except towards SE where a positive signal is still present. This wavelength is coherent with Pohl et al. (1988), but these authors did not precisely locate the maximum and underestimated the amplitude of the magnetic anomaly. Glass et al. (2012, and references within) also did not show details about this anomaly, although it still appears to be intense at the altitude of their airborne survey.

The maximum of the ground anomaly consists of a local sharp transition where a $20 \mathrm{nT} / \mathrm{m}$ vertical gradient was measured (Figure $2 \mathrm{C}$ ). This suggests that the top of the magnetized source occurs at very shallow depths in or below the impact melt sheet at Anomaly Hill.

\subsection{Acquisition time and type of magnetization}

The clasts of the impact melt rock should have acquired their magnetization during cooling of the melt sheet in the geomagnetic field at the time of impact (e.g., Koch et al., 2012). Indeed, the melt rock matrix contains carbonate melts with liquidus temperatures of about $500-600^{\circ} \mathrm{C}$ (Osinski et al., 
2005c), which is above the maximum blocking temperature of most clasts whose magnetic mineralogy is dominated by pyrrhotite with a Curie temperature of $320^{\circ} \mathrm{C}$ (see Figure 1 of the Supplementary Material). The 20 clasts sampled in the impact melt rocks show a single component of magnetization (Figure 3). The two sites provide undistinguishable mean paleomagnetic directions. The mean direction computed from individual clast direction is $\mathrm{I}=71^{\circ}, \mathrm{D}=341^{\circ}\left(\alpha_{95}=6.4^{\circ}, \mathrm{n}=16 / 20\right.$; see Figure 2 of the Supplementary Material), in agreement with a normal polarity regional direction of the time-averaged geomagnetic field at the impact location at $\sim 39 \mathrm{Ma}$ $\left(\mathrm{I}=80^{\circ}, \mathrm{D}=-34^{\circ}\right.$; Besse and Courtillot, 2002). This direction is also close to the direction of the geomagnetic field in $2010\left(\mathrm{I}=87^{\circ}, \mathrm{D}=-41^{\circ}\right.$; Finlay et al., 2010). Therefore, because induced (i.e., due to the present field) and measured remanent magnetizations have similar directions (angle of $16^{\circ}$; see Figure 2 of the Supplementary Material), their sum (total magnetization) was used in the following models regardless of their respective contribution.

\subsection{Rock magnetism}

The measurements of magnetic susceptibility and NRM on rock samples show that all Palaeozoic sedimentary rocks, both inside and outside the crater, have total magnetization intensity weaker than $0.01 \mathrm{~A} / \mathrm{m}$ (Table 1 and Figure 4). Pyrrhotite is the main magnetic carrier of the remanent magnetization of these rocks (Figure 3 of the Supplementary Material). Among the 337 basement samples, only 4\% (12 samples), both from inside and outside the crater, show total magnetization intensities larger than $1 \mathrm{~A} / \mathrm{m}$ with a maximum of $7.4 \mathrm{~A} / \mathrm{m}$ for a basaltic clast from the melt rock (Figure 5). These 12 samples are either granites or diorites from outside the crater, or unusual 
clasts from the melt rock in the crater: basalts, diorites, mafic rocks. These clasts come from the Precambrian basement (where they occur as dykes and lenses) underlying the Palaeozoic sediments. The corresponding formations are minor in the Precambrian shield (Frisch and Trettin, 1991) as in the clast population (Redeker and Stoeffler, 1988). In the few clasts found nearby the magnetic center (Anomaly Hill area), both magnetite (and/or maghemite) and pyrrhotite can carry these large (mainly remanent) magnetizations (see Figures 4 and 5 of the Supplementary Material). Most basement samples, in particular all the gneisses, have low susceptibility (median value $3.010^{-4} \mathrm{SI}$ ) and low NRM (median value $1.210^{-2} \mathrm{~A} / \mathrm{m}$ ), resulting in a low total magnetization (median value $2.910^{-2} \mathrm{~A} / \mathrm{m}$ ). The median (mean) Koenigsberger ratio $(\mathrm{Q}$, remanent magnetization intensity over induced magnetization intensity) for basement clasts from inside the crater is 0.88 (resp. 1.82), indicating an approximately equivalent contribution of induced and remanent magnetization to the total magnetization (Table 1). It is noteworthy that the Koenigsberger ratio is significantly lower for basement samples collected outside the crater than for samples collected inside the crater (median $\mathrm{Q}=0.11$ against 0.88 , respectively). This is explained by the nature of the NRM of the samples from inside the crater. Indeed, these samples all come as clasts from the impact melt rock layer. Therefore, they carry a thermoremanent magnetization (TRM) acquired soon after the impact, whereas the remanent magnetization of basement samples from outside the crater may not be a TRM, but rather a chemical remanent magnetization (CRM), and moreover it was affected by more than 500 Myrs of viscous decay. 


\subsection{Magnetic source modeling}

After forward modeling, the best combination corresponds to 12 prisms that comprise a $0.7 \mathrm{~km}^{3}$ magnetized source body with a root at $1 \mathrm{~km}$ depth (see Table 1 of the Supplementary Material; Figure 6). It fits the data with $\sim 90 \%$ of accuracy, while this value reaches $98 \%$ for the local anomaly profile (see Figure 6 of the Supplementary Material). The resulting root is similar to the root suggested by Pohl et al. (1988), indicating that only the top core of the central uplift is more magnetized than the surrounding rocks. At shallow depths (i.e., less than $30 \mathrm{~m}$ ), several small isolated magnetized bodies are necessary to explain the local variations of the magnetic anomaly and vertical gradient signals over the maximum. Most prisms need a $1.5 \mathrm{~A} / \mathrm{m}$ magnetization to account for the anomaly, while the most superficial ones require a larger intensity that can reach $2.3 \mathrm{~A} / \mathrm{m}$ (Table 1 of Supplementary Material).

Using a structural index of 1 , a window size of $700 \mathrm{~m}$, a depth uncertainty less than $20 \%$ and the interpolated magnetic anomaly grid as inputs, the SED resulting solutions beneath the maximum of the anomaly are clustered with depths ranging from 25 to $45 \mathrm{~m}$ (see Figure 7 of the Supplementary Material). The local gradient profile was not considered during the SED calculations, leading to a deeper top of the source than expected at local scale. Then it only confirms that the top of the magnetic part of the central uplift is shallower than about $35 \mathrm{~m}$.

Using the GM-SYS module of the GEOSOFT Inc Oasis montaj software, the best model consists in a $\sim 1 \mathrm{~km}^{3}$ magnetic body with superficial branches buried in the first $10 \mathrm{~m}$ below the surface (see Figure 8 of the Supplementary 
Material). Therefore, all modeling approaches suggest that the source of this magnetic anomaly is a large magnetized body with a $1 \mathrm{~km}$-deep root and with a top composed of several isolated (but close) volumes that could be accessible by a 20-30 $\mathrm{m}$ deep drilling. This large body was already suggested by the model of Pohl et al. (1988) - same root, same mean magnetization - but no details about the shape and depth of its top were shown.

\section{Discussion}

Our investigations confirm that Palaeozoic sediments cannot contribute to the central magnetic anomaly at Haughton impact structure. Unexposed crystalline basement bodies are sometimes suggested as the magnetic source for impact magnetic anomalies (Ugalde et al., 2007). However, the low mean total magnetization of the basement samples and the rarity of samples possessing sufficient total magnetization argue against this hypothesis for the Haughton case. Furthermore, the vast majority of the basement clasts in the melt rocks inside the crater are gneisses (Redeker and Stoeffler, 1988), suggesting that the uplifted basement is mostly composed of gneisses, which have total magnetizations well below $1 \mathrm{~A} / \mathrm{m}$. The modeled pyramidal geometry of the source and its expected high porosity also argue against the hypothesis of an unexposed silicate impact melt body for the source of the magnetic anomaly, as proposed for Chesapeake Bay (Shah et al., 2005) or Ries (Pohl et al., 2010) craters. Therefore, we suggest that an additional impact-related process is required to enhance the induced and/or remanent magnetization of the rocks responsible for the anomaly. Experimental works have shown that shock can modify the intrinsic magnetic properties of rocks 
(e.g., Gattacceca et al., 2007), and lead to demagnetization or remagnetization (e.g., Gattacceca et al., 2010). Our rock magnetic measurements show that the dominant ferromagnetic mineral in the Paleozoic sedimentary target rocks and in the gneissic basement is pyrrhotite (see Figures 1 and 3 of the Supplementary Material). Pyrrhotite should have been largely remagnetized by impact pressures above 1 GPa (Rochette et al., 2003; Gilder et al., 2011). The intrinsic magnetic properties of pyrrhotite are also affected by shock (Gattacceca et al., 2007; Louzada et al., 2007). But neither the shock magnetization (less efficient than thermoremanent magnetization; see Gattacceca et al., 2008), nor the expected modifications can make the studied rocks magnetic enough to account for the observed magnetic anomaly.

Therefore, we suggest that the best hypothesis to account for this central magnetic anomaly is post-impact hydrothermal alteration of a basement core of the Haughton central uplift (Figure 7). There is widespread evidence of hydrothermal activity at Haughton, dominated by vugs and veins of calcite, sulfides and sulfates (Osinski et al., 2005a). Indeed the hot superficial impactite layer provided the heat that, in combination with the meteoric, postimpact lake and ground water circulation, led to hydrothermal alteration of the target rocks. Most of the outcrops showing hydrothermal-derived mineralizations are present at the base of the melt layer, which is best exposed around the edge of the central uplift (Osinski et al., 2005a). However, the more intense fracturing and porosity at the center of the Haughton structure - suggested by the low gravity anomaly, the low densities of highly-shocked basement clast densities (Singleton et al., 2011) and by the heterogeneity of the shallow part of our magnetic model - would have favored water cir- 
culation and associated hydrothermal activity at this location (Figure 7). Hydrothermal activity has been suggested as the process that creates the main magnetic anomaly in large impact craters, such as Chicxulub (Pilkington and Hildebrand, 2000; Escobar-Sanchez and Urrutia-Fucugauchi, 2010). For intermediate- and small-size craters, if post-impact hydrothermal activity occurred, to our knowledge, this process has not been invoked to produce a central magnetic anomaly to date (e.g., Pilkington and Grieve, 1992; Kenkmann et al., 2005).

Over Precambrian formations affected by low grade metamorphism and mineralization, pyrrhotite-bearing rocks and magnetite-bearing rocks are often responsible for local intense aeromagnetic anomalies (Airo, 2002). Interestingly, the remanence of such rocks is mainly carried by pyrrhotite (with low susceptibilities), while magnetite have high susceptibility and low remanence (Direen et al., 2008). Such remanence is often acquired through crystallization of pyrrhotite during retrograde low-level metamorphism when sulfides are remobilized in shear zones. On the other hand, magnetite is thought to be produced during prograde metamorphism (Direen et al., 2008). It means that local accumulations of any of these two minerals can occur during a mild thermal event, like in post-impact hydrothermal activity. Sulfides and sulfates are abundant in hydrothermal-derived parageneses around the edge of the central uplift at Haughton (Osinski et al., 2005a), which argues for post-impact crystallization of pyrrhotite (Kontny et al., 2007) in other areas of the crater, like the core of the central uplift. Magnetite of hydrothermal origin can also contribute to magnetic anomalies in impact craters, in association with pyrrhotite (Mang et al., 2012). These newly-formed min- 
erals carry a chemical or thermo-remanent magnetization. Using reasonable assumptions about the intrinsic magnetic properties of pyrrhotite and magnetite as well as about the efficiency of chemical and thermo-remanent magnetization, it appears that the crystallization of about $0.1 \mathrm{wt} \%$ (resp. 0.6 wt.\%) of magnetite (resp. pyrrhotite) is enough to account for a total magnetization of $1 \mathrm{~A} / \mathrm{m}$ (see explanations at the end of the Supplementary Material). Such concentrations are consistent with those measured in some other hydrothermal systems (see Clark, 1999, and references within). An alternative impact-generated process that can lead to the production of finegrained magnetite is shock-wave decomposition of the target mafic minerals (Pohl et al., 2010). This could explain the presence of magnetite in the rare highly-shocked strongly-magnetized clasts (see Figures 4 and 5 of the Supplementary Material), and, perhaps, associated with pyrrhotite in the uplifted gneissic basement.

If hydrothermalism occurred and enhanced the initial magnetization of the target rocks at Haughton, it implies that a similar process may have occurred on other terrestrial planets. It requires the presence of subsurface water, of an ambient magnetic field and of iron-bearing rocks in the target crust. Concerning subsurface water, among the possible candidates excepted the Earth, only Mars and possibly some asteroids are suitable. Indeed geological and morphological indices of impact-generated hydrothermalism have been observed on Mars (e.g., Marzo et al., 2010; Squyres et al., 2012; Osinski et al., in press (online publication Oct 2012)). Numerical modeling is also suggestive of its occurence for Martian craters (Abramov and Kring, 2005; Rathbun and Squyres, 2002). However, the high-altitude of the mag- 
netic field measurements made on Mars prevents the detection of magnetic anomalies over impact craters with diameter less than $200 \mathrm{~km}$ (Langlais and Thébault, 2011). Therefore, new low-altitude surveys are necessary to unveil such central magnetic anomalies. Nevertheless, hydrothermalism has probably occurred and enhanced the crustal magnetization on early Mars not only after impacts (external origin), but also because large heat sources from the early Martian mantle are expected and may have led to the hydrothermal alteration of a large part of the crust (e.g., Meunier et al., 2012; Quesnel et al., 2009). However, near-surface hydrothermal activity in impact craters (sometimes with lake) constitutes an excellent place for the initiation, development and long-term existence for life (e.g., Cockell et al., 2010).

\section{Conclusion}

The objective of this study was to determine the nature of the magnetized source responsible for the intense central magnetic anomaly observed within the Haughton impact structure by investigating the geometry and magnetization of this source. We found that no target rocks at Haughton possess a total magnetization large enough to account for the magnetic anomaly, except a small fraction (4\%) of unusual basement samples. The high density of these rare samples is incompatible with the negative gravity anomaly. It is therefore probable that the actual magnetic source lithology is not exposed in the crater and is not found as basement clasts within the melt rock sheet. Using different modeling methods, we concluded that the magnetic source body has a 1-km deep root but a very superficial top (less than $10 \mathrm{~m}$ ) that could be drilled in a future mission. The enhancement of the total mag- 
netization of this source is best explained by impact-generated hydrothermal activity favored by intense fracturing and high porosity of the uplifted basement (low gravity anomaly), leading to the crystallization of magnetite and/or pyrrhotite. Our model thus explains the association of a large central magnetic anomaly with a low gravity anomaly over this impact structure. This may help for the interpretation of the low-altitude geophysical signature of impact craters on other planets, and confirms that impact structures are ideal places for life. In addition, our study shows that the impact took place during a normal polarity interval of the geomagnetic field, providing an additional chronologic constraint.

\section{Acknowledgments}

This work was funded by IPEV and ANR (Project ANR-09-BLAN-0042). GRO acknowledges funding from NSERC, CSA, and MDA through sponsorship of his Industrial Research Chair. JG acknowledges funding from People Programme (Marie Curie Actions of the European Union, REA grant agreement N298355. The authors are grateful to the Polar Continental Shelf Project for their logistical support, to A. Deutsch and U. Heitmann for access to their Devon Island samples at the Institute for Planetology in Münster (Germany), to J. Pohl and two anonymous reviewers for their helpful comments, as well as to F. Demory for his help during the rock magnetic measurements. Some figures were built with the Generic Mapping Tools (GMT) software (Wessel and Smith, 1998). 


\section{References}

Abramov, O., Kring, D., 2005. Impact-induced hydrothermal activity on early Mars. J. Geophys. Res. 110 (E12S09).

Airo, M.-L., 2002. Aeromagnetic and aeroradiometric response to hydrothermal alteration. Surveys in Geophysics 23, 273-302.

Besse, J., Courtillot, V., 2002. Apparent and true polar wander and the geometry of the geomagnetic field over the last 200 Myr. J. Geophys. Res. 107 (B11), 2300.

Bischoff, L., Oskierski, W., 1988. The surface structure of the Haughton impact crater, Devon Island, Canada. Meteoritics 23, 209-220.

Buczkowski, D. L., Frey, H. V., Roark, J. H., McGill, G. E., 2005. Buried impact craters: A topographic analysis of quasi-circular depressions, Utopia Basin, Mars. J. Geophys. Res. 110 (E9), 3007.

Campbell, D., 1983. Basic programs to calculate gravity and magnetic anomalies for 2-1/2 - dimensional prismatic bodies. Open-file report 83154, U.S. Geological Survey.

Clark, D., 1999. Magnetic petrology of igneous intrusions: implications for exploration and magnetic interpretation. Expl. Geoph. 30, 5-26.

Cockell, C., Lee, P., Osinski, G., Horneck, G., Broady, P., 2010. Impactinduced microbial endolithic habitats. Meteorit. Planet. Sci. 37, 1287-1298. 
Cogné, J.-P., 2003. PaleoMac: A Macintosh application for treating paleomagnetic data and making plate reconstructions. Geochem. Geophys. Geosyst. 4 (1), 1007, doi:10.1029/2001GC00027.

Direen, N., Pfeiffer, K., Schmidt, P., 2008. Strong remanent magnetization in pyrrhotite: A structurally controlled example from the Paleoproterozoic Tanami orogenic gold province, northern Australia. Precambrian Research $165,96-106$.

Escobar-Sanchez, J., Urrutia-Fucugauchi, J., 2010. Chicxulub crater postimpact hydrothermal activity evidence from the Paleocene carbonates in the Santa Elena borehole. Geofisica Internacional 49, 97-106.

Finlay, C. C., Maus, S., Beggan, C. D., Bondar, T. N., Chambodut, A., Chernova, T. A., Chulliat, A., Golovkov, V. P., Hamilton, B., Hamoudi, M., Holme, R., Hulot, G., Kuang, W., Langlais, B., Lesur, V., Lowes, F. J., Lühr, H., MacMillan, S., Mandea, M., McLean, S., Manoj, C., Menvielle, M., Michaelis, I., Olsen, N., Rauberg, J., Rother, M., Sabaka, T. J., Tangborn, A., Töffner-Clausen, L., Thébault, E., Thomson, A. W. P., Wardinski, I., Wei, Z., Zvereva, T. I., 2010. International Geomagnetic Reference Field: the eleventh generation. Geophys. J. Int. 183, 1216-1230. Frey, H. V., Shockey, K. M., Frey, E. L., Roark, J. H., Sakimoto, S. E. H., 2001. A Very Large Population of Likely Buried Impact Basins in the Northern Lowlands of Mars Revealed by MOLA Data. In: Lunar and Planetary Institute Science Conference Abstracts. Vol. 32. p. 1680.

Frisch, T., Trettin, H., 1991. Precambrian successions in the northernmost 
part of the Canadian Shield. In: Trettin, H. (Ed.), Geology of the Innuitian Orogen and Arctic Platform of Canada and Greenland, Geological Survey of Canada, Geology of Canada 3. Geological Survey of Canada, Ottawa, pp. 103-108.

Gattacceca, J., Berthe, L., Boustie, M., Vadeboin, F., Rochette, P., de Resseguier, T., 2008. On the efficiency of shock magnetization processes. Phys. Earth Planet. Int. 166, 1-10.

Gattacceca, J., Boustie, M., Lima, E., Weiss, B., de Resseguier, T., CuqLelandais, J.-P., 2010. Unraveling the simultaneous shock magnetization and demagnetization of rocks. Phys. Earth Planet. Int. 182, 42-49.

Gattacceca, J., Lamali, A., Rochette, P., Berthe, L., 2007. The effects of explosive-driven shocks on the natural remanent magnetization and the magnetic properties of rocks. Phys. Earth Planet. Int. 162, 85-98.

Gilder, S. A., Egli, R., Hochleitner, R., Roud, S. C., Volk, M. W. R., Le Goff, M., de Wit, M., 2011. Anatomy of a pressure-induced, ferromagnetic-toparamagnetic transition in pyrrhotite: Implications for the formation pressure of diamonds. J. Geophys. Res. 116 (B15), doi:10.1029/2011JB008292.

Glass, B., Domville, S., Sanjanwala, R., Lee, P., 2012. Constrained model interpretations from Haughton crater geophysical datasets. In: Houston, Texas, Lunar and Planetary Institute, Lunar and Planetary Science XLIII. p. abs. 2910.

Grieve, R. A. F., 1987. Terrestrial Impact Structures. Ann. Rev. Earth Planet Sci. 15, 245-270. 
Henkel, H., Reimold, W., Koeberl, C., 2002. Magnetic and gravity model of the Morokweng impact structure. J. Appl. Geophys. 49, 129-147.

Hickey, L., Johnson, K., Dawson, M., 1988. The stratigraphy, sedimentology, and fossils of the Haughton formation: a post-impact crater-fill, Devon Island, N.W.T., Canada. Meteoritics 23, 221-231.

Kenkmann, T., Hoerz, F., Deutsch, A., 2005. Large meteorite impacts III. Boulder, Colorado, Geological Society of America Special Paper 384.

Koch, S. A., Gilder, S. A., Pohl, J., Trepmann, C., 2012. Geomagnetic field intensity recorded after impact in the Ries meteorite crater, Germany. Geophys. J. Int. 189, 383-390.

Kontny, A., Elbra, T., Just, J., Pesonen, L., Schleicher, A., Zolk, J., 2007. Petrography and shock related remagnetization of pyrrhotite in drill cores from Bosumtwi Impact Crater drilling project, Ghana. Meteorit. Planet. Sci. $42,811-827$.

Langlais, B., Thébault, E., 2011. Predicted and observed magnetic signatures of martian (de)magnetized impact craters. Icarus 212, 568-578.

Louzada, K., Stewart, S., Weiss, B., 2007. Effect of shock on the magnetic properties of pyrrhotite, the Martian crust, and meteorites. Geophys. Res. Lett. 34 (5204).

Mang, C., Kontny, A., Harries, D., Langenhorst, F., Hecht, L., 2012. Iron deficiency in pyrrhotite of suevites from the Chesapeake Bay impact crater, USA - A consequence of shock-metamorphism? Meteorit. Planet. Sci. 47, $277-295$. 
Marzo, G., Davila, A., Tornabene, L., Dohm, J., Fairén, A., Gross, C., Kneissl, T., Bishop, J., Roush, T., McKay, C., 2010. Evidence for Hesperian impact-induced hydrothermalism on Mars. Icarus 208, 667-683.

Melosh, H., 1989. Impact cratering: a geologic process. New York, Oxford University Press, 253 p.

Metzler, A., Ostertag, R., Redeker, H., Stöffler, D., 1988. Composition of the crystalline basement and shock metamorphism of crystalline and sedimentary target rocks at the Haughton impact crater, Devon Island, Canada. Meteoritics 23, 197-207.

Meunier, A., Petit, S., Ehlmann, B., Dudoignon, P., Westall, F., Mas, A., El Albani, A., Ferrage, E., 2012. Magmatic precipitation as a possible origin of Noachian clays on Mars. Nature Geoscience 5, doi:10.1038/NGEO1572.

Osinski, G., Lee, P., Parnell, J., Spray, J., Baron, M., 2005a. A case study of impact-induced hydrothermal activity: The Haughton impact structure, Devon Island, Canadian High Arctic. Meteorit. Planet. Sci. 40 (12), 18591878.

Osinski, G., Lee, P., Spray, J., Parnell, J., Lim, D., Bunch, T., Cockell, C., Glass, B., 2005b. Geological overview and cratering model for the Haughton impact structure, Devon Island, Canadian High Arctic. Meteorit. Planet. Sci. 40 (12), 1759-1776.

Osinski, G., Spray, J., 2005. Tectonics of complex crater formation as revealed by the Haughton impact structure, Devon Island, Canadian High Arctic. Meteorit. Planet. Sci. 40 (12), 1813-1834. 
Osinski, G., Spray, J., Lee, P., 2005c. Impactites of the Haughton impact structure, Devon Island, Canadian High Arctic. Meteorit. Planet. Sci. 40 (12), 1789-1812.

Osinski, G., Tornabene, L., Banerjee, N., Cockell, C., Flemming, R., Izawa, M., McCutcheon, J., Parnell, J., Preston, L., Pickersgill, A., Pontefract, A., Sapers, H., Southam, G., in press (online publication Oct 2012). Impact-generated hydrothermal systems on Earth and Mars. Icarus, doi:10.1016/j.icarus.2012.08.030.

Pilkington, M., Grieve, R., 1992. The geophysical signature of terrestrial impact craters. Rev. Geophys. 30, 161-181.

Pilkington, M., Hildebrand, A., 2000. Three-dimensional magnetic imaging of the Chicxulub Crater. J. Geophys. Res. 105, 23479-23492.

Pohl, J., Eckstaller, A., Robertson, P., 1988. Gravity and Magnetic Investigations in the Haughton Impact Structure, Devon Island, Canada. Meteoritics $23,235-238$.

Pohl, J., Poschlod, K., Reimold, W., Meyer, C., Jacob, J., 2010. Ries crater, Germany: The Enkingen magnetic anomaly and associated drill core SUBO 18. In: Large Meteorite Impacts and Planetary Evolution IV. Vol. 465. Geological Society of America Special Papers, pp. 141-163.

Quesnel, Y., Langlais, B., Sotin, C., Galdeano, A., 2008. Modelling and inversion of local magnetic anomalies. J. Geophys. Eng. 5, 387-400.

Quesnel, Y., Sotin, C., Langlais, B., Costin, S., Mandea, M., Gottschalk, M., 
Dyment, J., 2009. Serpentinization of the martian crust during Noachian. Earth Planet Sci. Lett. 277, 184-193, doi:10.1016/j.epsl.2008.10.012.

Rathbun, J., Squyres, S., 2002. Hydrothermal systems associated with Martian impact craters. Icarus 157, 362-372.

Redeker, H., Stoeffler, D., 1988. The allochthonous polymict breccia layer of the Haughton impact crater, Devon Island, Canada. Meteoritics 23, 185196.

Reid, A., Allsop, J., Granser, H., Millett, A., Somerton, I., 1990. Magnetic interpretation in three dimensions using Euler deconvolution. Geophysics 55 (1), 80-91.

Robertson, P., Sweeney, J., 1983. Haughton impact structure: structural and morphological aspects. Can. J. Earth. Sci. 20 (7), 1134-1151.

Rochette, P., Fillion, G., Ballou, R., Brunet, F., Ouladdiaf, B., Hood, L., 2003. High pressure magnetic transition in pyrrhotite and impact demagnetization on Mars. Geophys. Res. Lett. 30 (13).

Scott, D., Hajnal, Z., 1988. Seismic signature of the Haughton structure. Meteoritics 23, 239-247.

Shah, A., Brozena, J., Vogt, P., Daniels, D., Plescia, J., 2005. New surveys of the Chesapeake Bay impact structure suggest melt pockets and targetstructure effect. Geology 33, 417-420.

Singleton, A., Osinski, G., McCausland, P., Moser, D., 2011. Shock-induced changes in density and porosity in shock-metamorphosed crystalline rocks, 
Haughton impact structure, Canada. Meteorit. Planet. Sci. 46 (11), 17741786.

Squyres, S. W., Arvidson, R. E., Bell, J. F., Calef, F., Clark, B. C., Cohen, B. A., Crumpler, L. A., de Souza, P. A., Farrand, W. H., Gellert, R., Grant, J., Herkenhoff, K. E., Hurowitz, J. A., Johnson, J. R., Jolliff, B. L., Knoll, A. H., Li, R., McLennan, S. M., Ming, D. W., Mittlefehldt, D. W., Parker, T. J., Paulsen, G., Rice, M. S., Ruff, S. W., Schröder, C., Yen, A. S., Zacny, K., 2012. Ancient Impact and Aqueous Processes at Endeavour Crater, Mars. Science 336, 570-576, doi:10.1126/science.1220476.

Ugalde, H., Morris, W., Pesonen, L., Danuor, S., 2007. The Lake Bosumtwi meteorite impact structure, Ghana - Where is the magnetic source? Meteorit. Planet. Sci. 42, 867-882.

Wessel, P., Smith, W. H. F., 1998. New, improved version of generic mapping tools released. EOS Transactions 79, 579 . 
Figure 1: Location and geology of the Haughton impact structure. On top-left location map, RES corresponds to the RESolute magnetic observatory located at $170 \mathrm{~km}$ from the Haughton crater. On the central map, the surveyed area is indicated by the white broken box with letter ' $\mathrm{M}$ ' indicating the peak of the central magnetic anomaly, located at $\mathrm{E}$ 424677 m, N 8367960 m in the North American Datum 1927 system. This 'M' point is used as origin for all magnetic maps and profiles. The two stars indicate the two sites where the impact melt rock was sampled for paleomagnetism, while the dashed circles represent the external and internal limits of a well-fractured zone with radial and concentric faults. Lithologies: 1, Quaternary fluvial and fluvioglacial sediments; 2, Haughton formation (lacustrine sediments); 3, Impact melt rocks; 4 and 5, Upper Ordovician to Silurian Allen Bay formation, Middle (dolomite) and Lower (limestone) Members, respectively; 6, Middle to Upper Ordovician Thumb Mountain formation (limestone and dolomite); 7, Middle Ordovician Bay Fiord formation (anhydrite and dolomite); 8, Lower to Middle Ordovician Eleanor River formation (limestone and dolomite).

Figure 2: Raw total-field measurements (A), interpolated magnetic field anomaly map (B) and local vertical gradient E-W profile over the magnetic center (C). The background on (A) shows the topographical contours of the studied area, while point 'M' denotes the maximum of the magnetic anomaly, chosen as origin for all maps and profiles. The location of the gradient profile $(\mathrm{C})$ is shown by a thin black line over this maximum on the anomaly map (B). On (C), HP means High Probe signal (1.5 m above the ground), LP means Low Probe signal (0.5 m above the ground), while GD means Gradient signal. 'f.m.c.' means 'from magnetic center'.

Figure 3: Orthogonal projection plots of stepwise thermal demagnetization data of sedimentary and basement clasts from the impact melt rock. Open and solid symbols are projections on vertical and horizontal planes, respectively. Demagnetization steps are indicated in ${ }^{\circ} \mathrm{C}$. NRM means Natural Remanent Magnetization. 
Figure 4: Mean total (induced + remanent) magnetization (Mtot) and Koenigsberger ratio $(\mathrm{Q}$, ratio of remanent over induced magnetization) of all target formations. The range is indicated by the 'error' bars. The gray area in the total magnetization diagram indicates the range of values $(1.5-2.3 \mathrm{~A} / \mathrm{m})$ necessary for the source of the magnetic anomaly (see text). Acronyms are: AB, Allen Bay formation; TM, Thumb Mountain formation; BF, Bay Fiord formation; ER, Eleanor River formation; CO, other Cambrian-Ordovician sedimentary formations sampled outside the crater; PB, Precambrian Basement.

Figure 5: Frequency histogram of total magnetization for 337 basement samples from Devon Island (316 from inside the crater, 21 from outside the crater). Note the log scale for total magnetization.

Figure 6: 3D view showing the resulting 12-prisms forward model of the magnetic source of the central magnetic anomaly observed at Haughton. The brown level of each uniformly magnetized prism depends on its magnetization (brown scale in $\mathrm{A} / \mathrm{m}$ ). The surface over these prisms corresponds to the interpolated magnetic anomaly grid seen on Figure 2B with relief and color level depending on the anomaly intensity (in nT). The top right panel zooms in the superficial prisms. Same origin as for the map of Figure 1. 'f.m.c.' means 'from magnetic center'.

Figure 7: Schematic representation of the post-impact hydrothermal alteration that enhanced the magnetization in the porous core (dotted area) of the central uplift due to concentrations of newly-formed pyrrhotite and/or magnetite mineralizations. 
- We investigate the source of the central magnetic anomaly at the Haughton impact structure.

- A large magnetized body with superficial branches and with 1.5 to $2.3 \mathrm{~A} / \mathrm{m}$ magnetization intensities is discovered.

- No visible rocks can carry such magnetization.

- Post-impact hydrothermal activity at the top of the central uplift may have enhanced the initial basement rock magnetization. 
Click here to download high resolution image

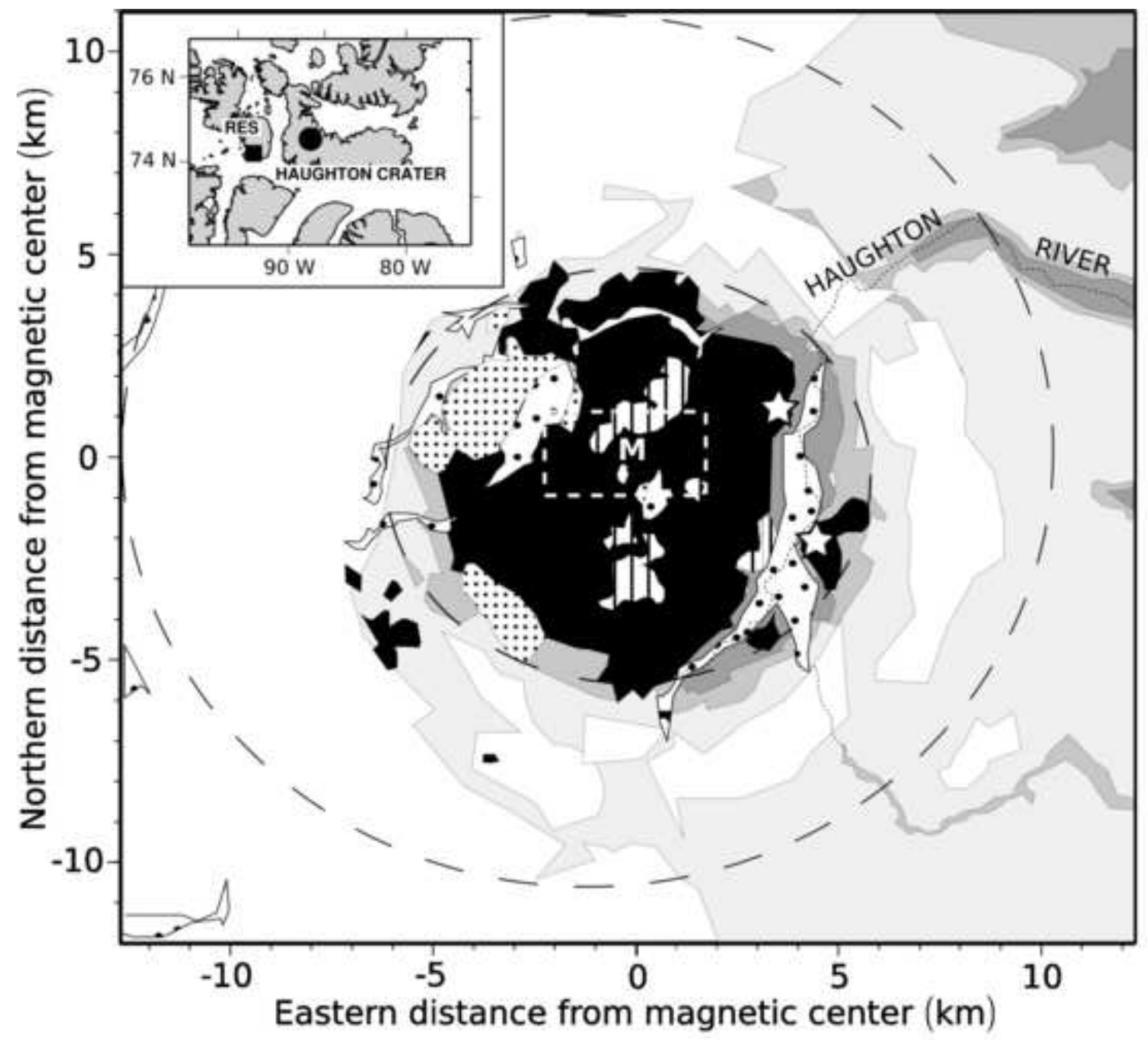

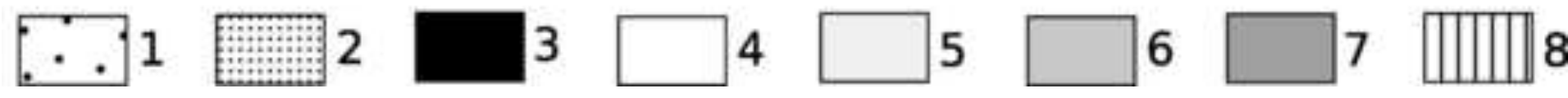


Click here to download high resolution image
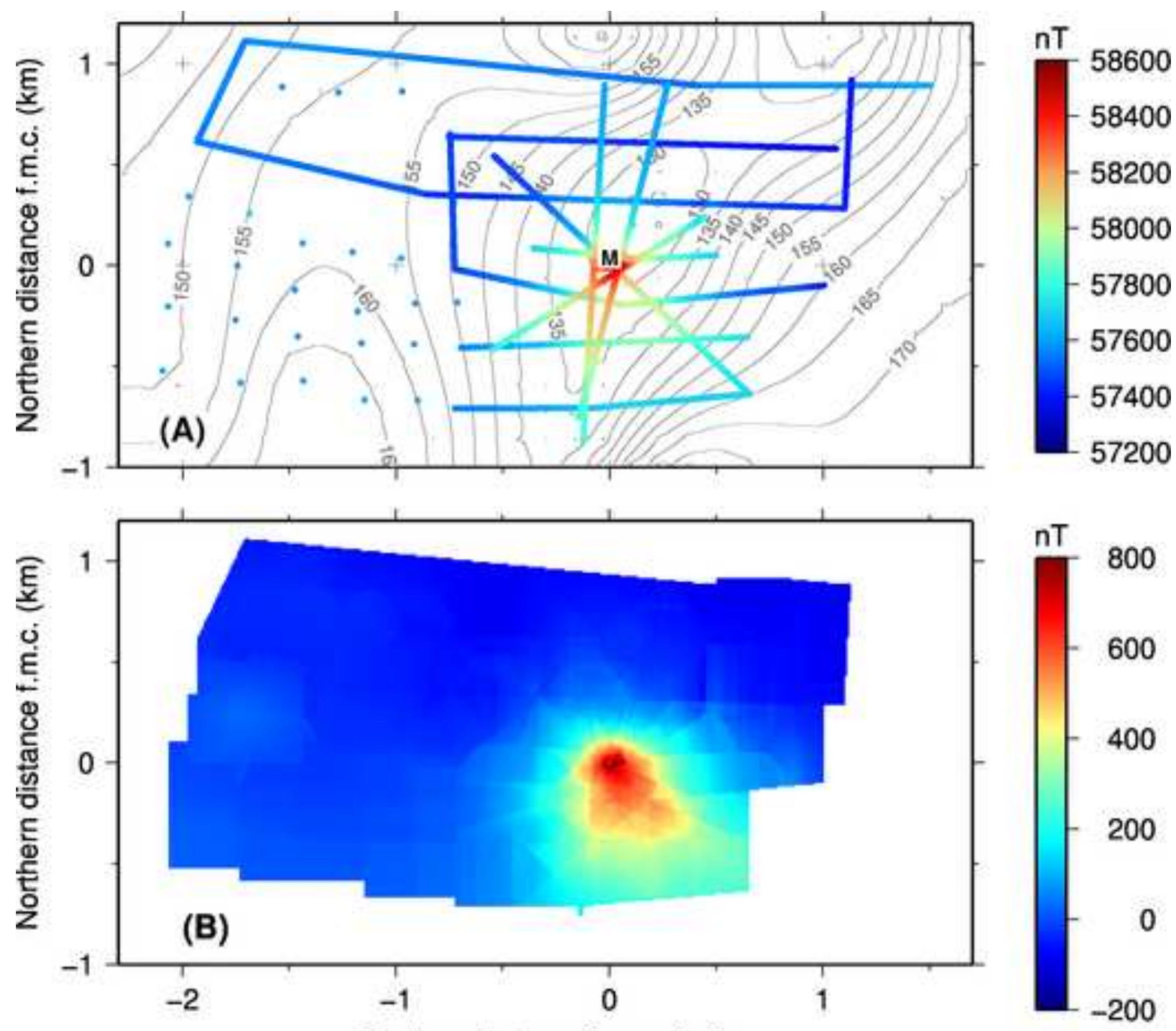

Eastern distance f.m.c. (km)

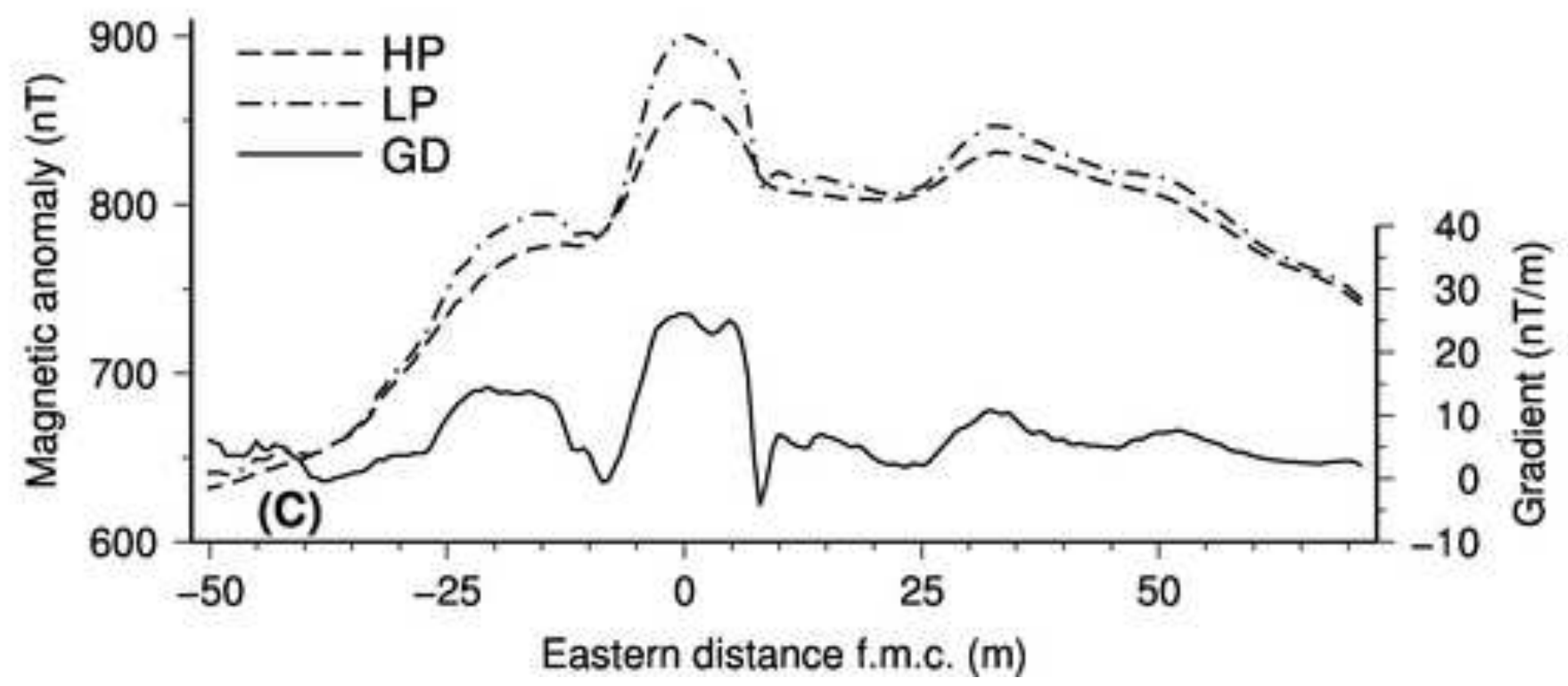




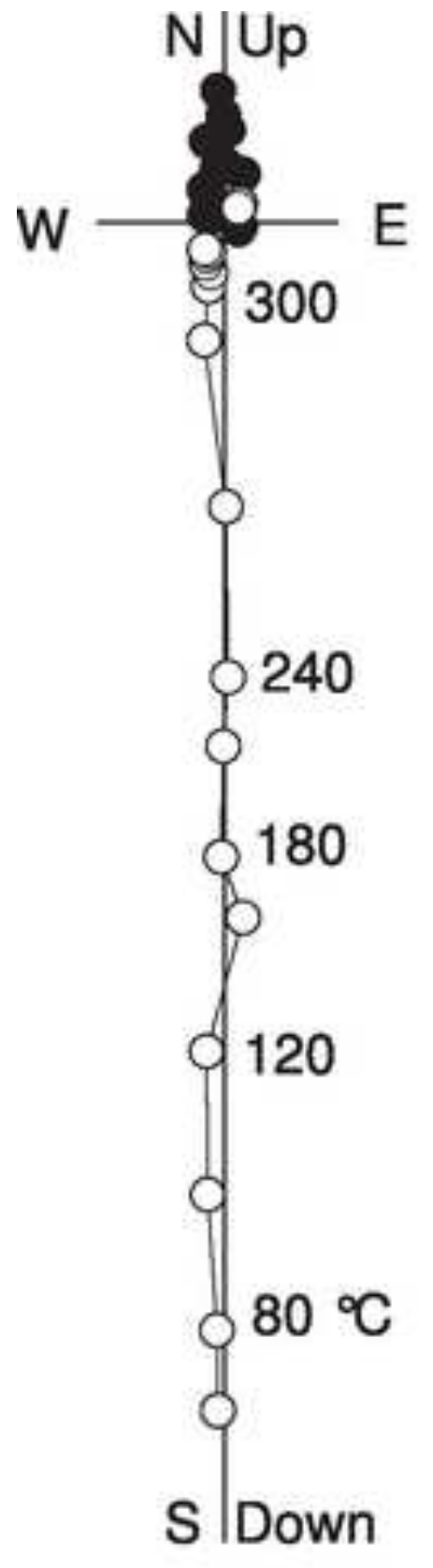

Gneiss

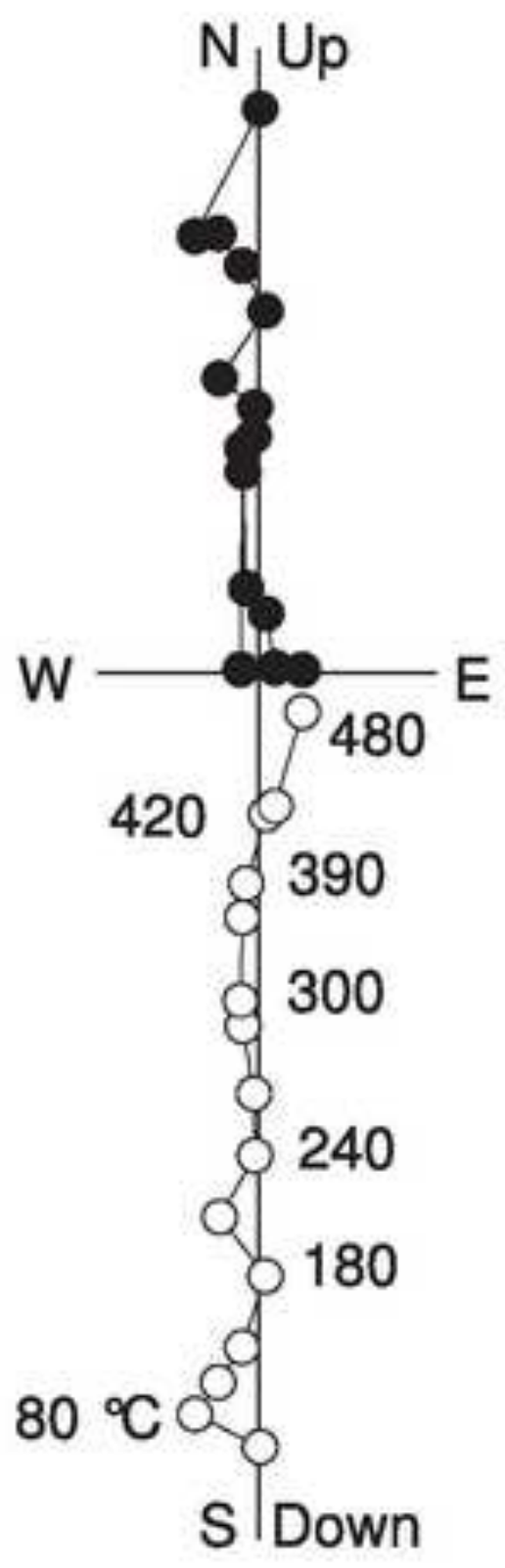

Granitoid

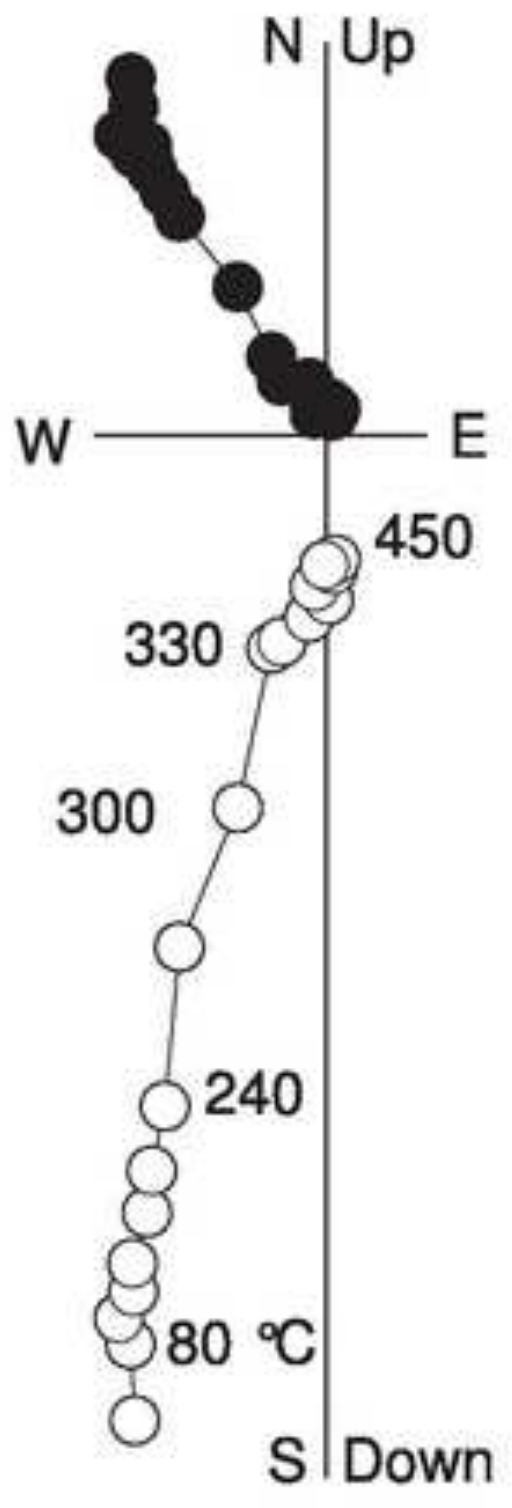

Limestone

$\mathrm{NRM}=0.349 \mathrm{~A} / \mathrm{m}$ 

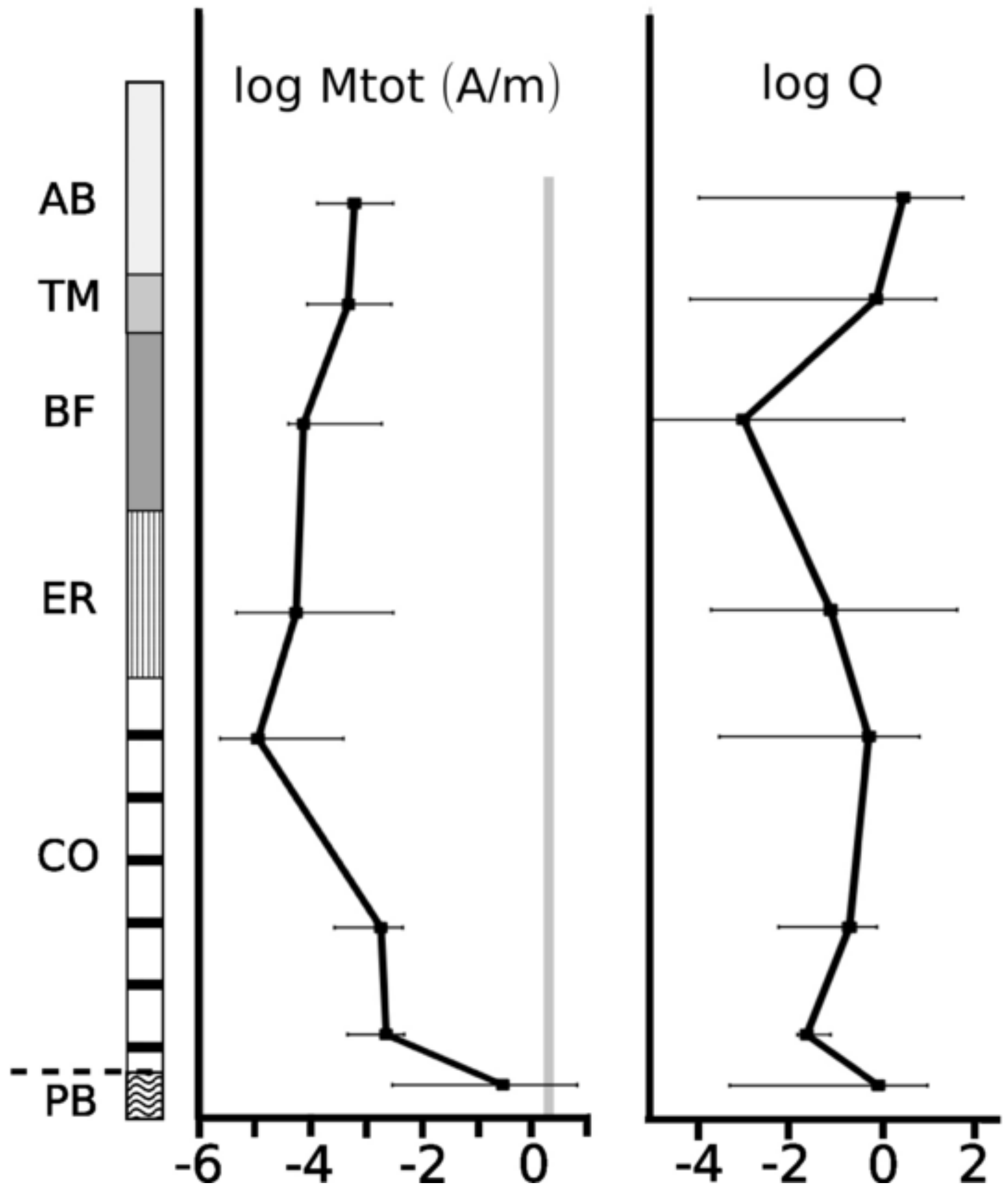


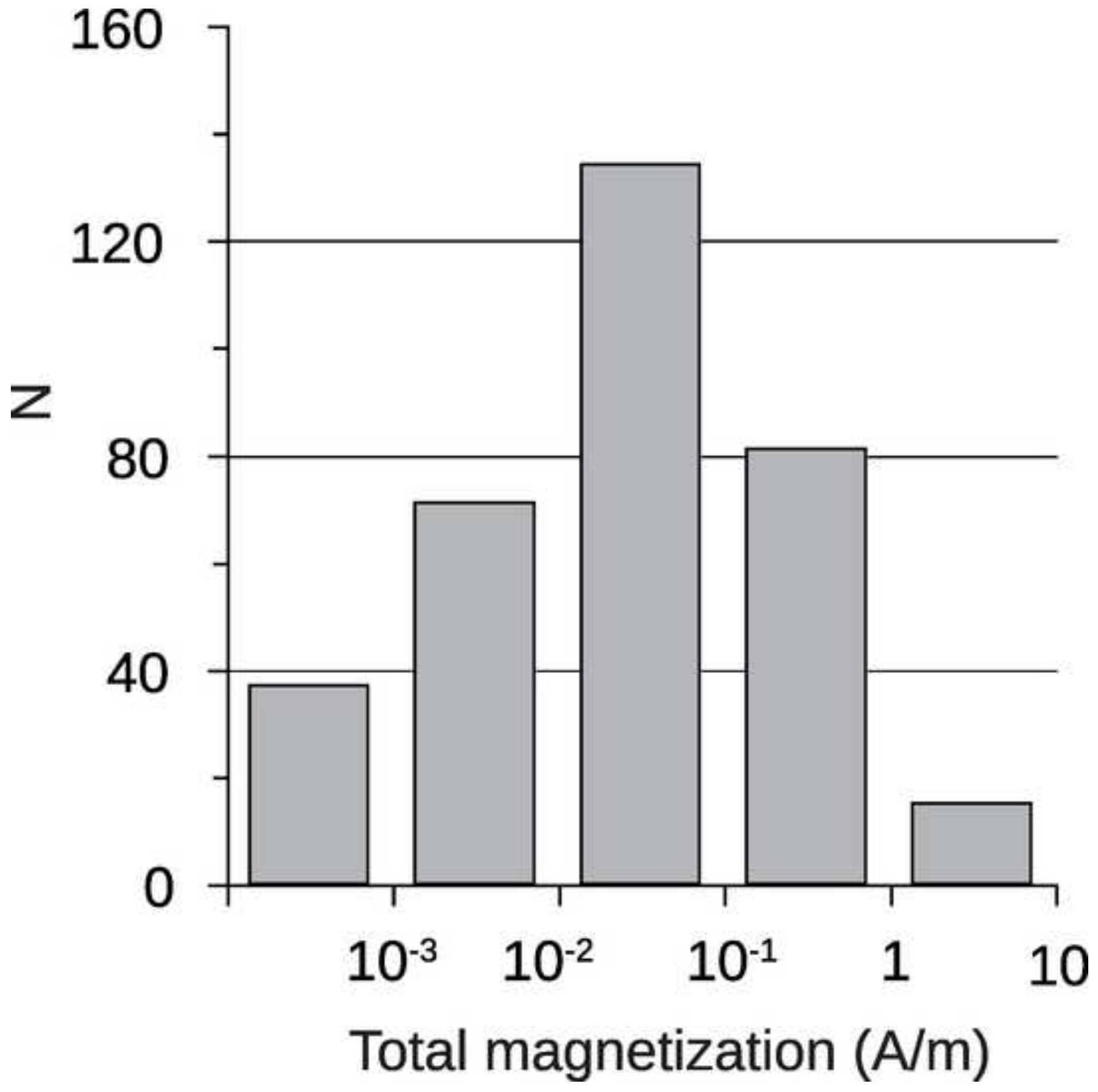




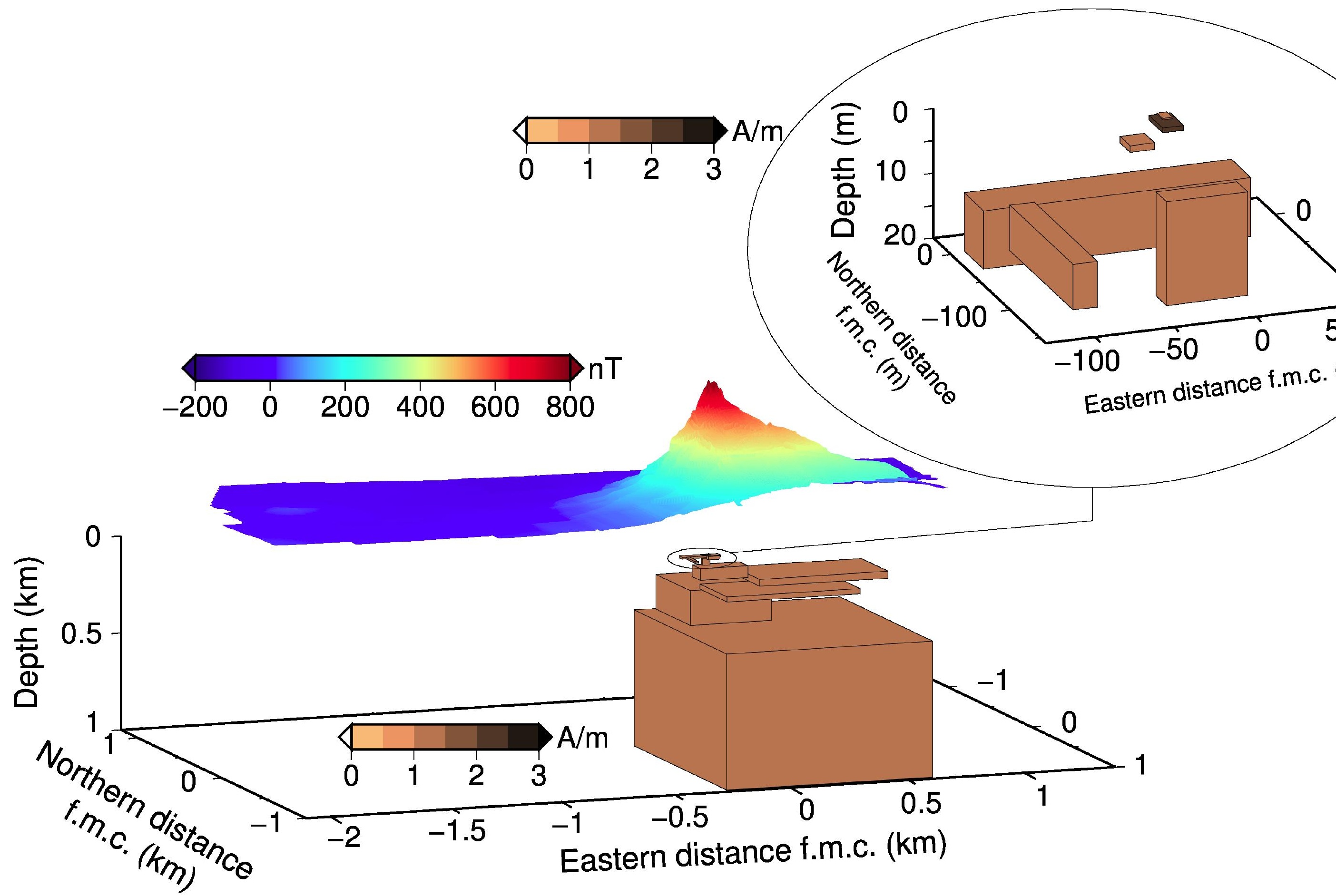



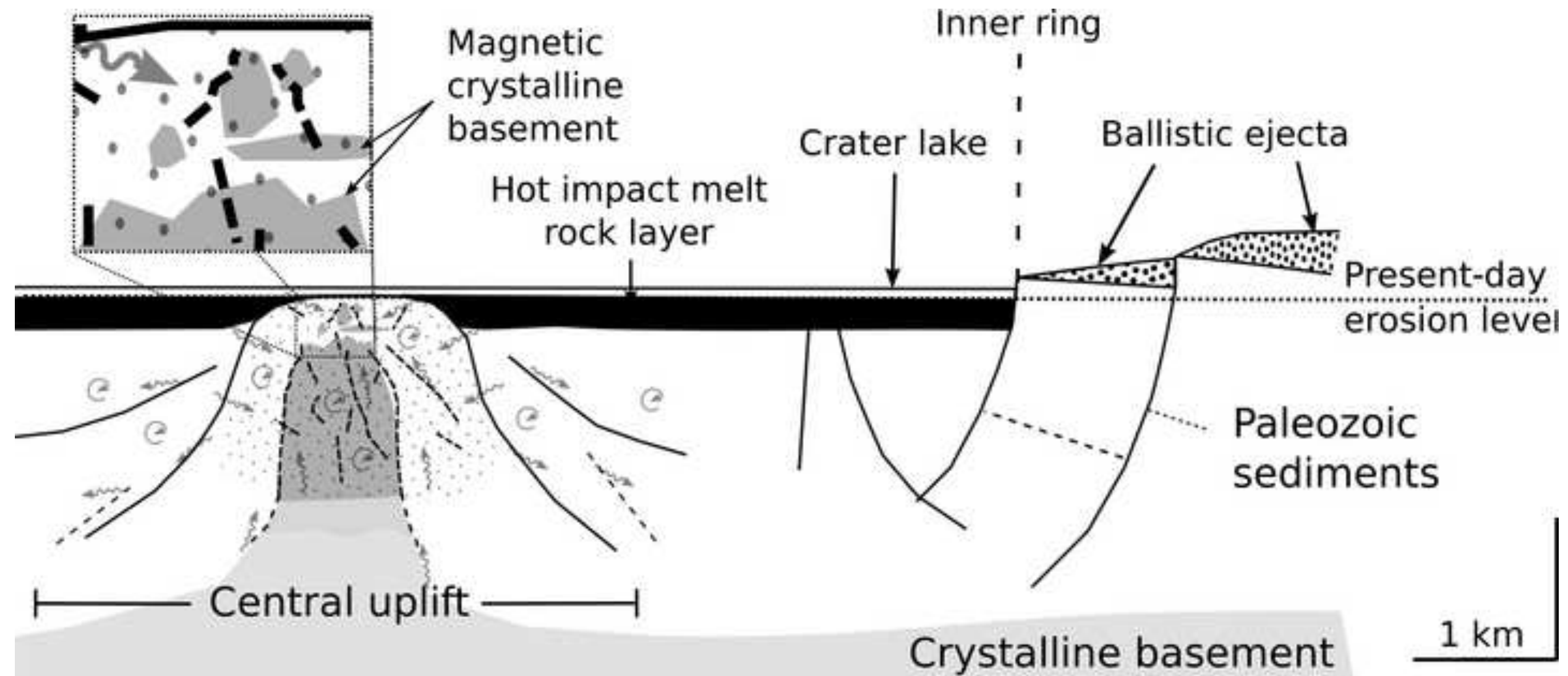

Crystalline basement 
Table 1: Magnetic properties of Haughton target rocks.

\begin{tabular}{lccccccccc}
\hline Name of formation & $\mathrm{N}$ & \multicolumn{2}{c}{$\mathrm{K}\left(10^{-3} \mathrm{SI}\right)$} & \multicolumn{2}{c}{$\mathrm{NRM}\left(10^{-3} \mathrm{~A} / \mathrm{m}\right)$} & \multicolumn{2}{c}{ Mtot $\left(10^{-3} \mathrm{~A} / \mathrm{m}\right)$} & \multicolumn{2}{c}{$\mathrm{Q}$} \\
& & Mean & Max & Mean & Max & Mean & Max & Mean & Max \\
\hline Allen Bay & 25 & 0.006 & 0.025 & 0.347 & 1.523 & 0.601 & 2.524 & 2.74 & 52.89 \\
Thumb Mountain & 42 & 0.006 & 0.038 & 0.186 & 0.688 & 0.460 & 2.419 & 0.73 & 14.02 \\
Bay Fiord & 39 & -0.004 & 0.026 & 0.095 & 0.654 & 0.069 & 1.854 & 0.04 & 2.80 \\
Eleanor River & 108 & -0.005 & 0.007 & 0.200 & 3.343 & 0.051 & 3.086 & 0.07 & 39.86 \\
Blanley Bay & 20 & -0.002 & 0.007 & 0.085 & 0.249 & 0.010 & 0.367 & 0.50 & 6.22 \\
Cass Fiord & 24 & 0.038 & 0.060 & 0.142 & 0.458 & 1.858 & 2.802 & 0.19 & 0.75 \\
Bear Point & 11 & 0.050 & 0.057 & 0.051 & 0.138 & 2.319 & 2.689 & 0.02 & 0.07 \\
Basement (inside) & 316 & 2.260 & 89.90 & 97.00 & 3610. & 215.0 & 7350 & 1.82 & 9.21 \\
Basement (outside) & 21 & 7.400 & 89.20 & 88.50 & 476.0 & 443.0 & 4740 & 0.33 & 1.18 \\
\hline
\end{tabular}

N, number of studied samples; K, magnetic susceptibility; NRM, Natural Remanent Magnetization; Mtot, total (induced + remanent) magnetization intensity; Q, Koenigsberger ratio (remanent over induced magnetization ratio). 